\title{
COVID-19, Sex, Addictions, Women's Health, Care of the Elderly, and Medical Education
}

\section{Lindsay B. Carey ${ }^{1} \cdot$ Jeffery Cohen ${ }^{2,3} \cdot$ Harold G. Koenig ${ }^{4,5,6} \cdot$ Ezra Gabbay $^{7}$. Jacinda R. Carey ${ }^{1}$}

Accepted: 13 April 2021 / Published online: 6 May 2021

(c) The Author(s), under exclusive licence to Springer Science+Business Media, LLC, part of Springer Nature 2021

\section{Introduction}

A variety of topics have been covered in this third issue of JORH for 2021, namely: (i) COVID-19, (ii) sex, (iii) addictions, (iv) women's health, (v) care of the aged, and (vi) medical education (JORH, 2021).

\section{COVID-19}

As noted in the last editorial, despite the development of vaccines, COVID-19 continues to be a significant determinant of biological, psychological, sociological, economic, and theological aspects of life-a dynamic which looks to continue throughout 2021 (Carey et al., 2021). Thus far (at the time of writing, April 2021), approximately 134 million people worldwide have been infected (estimated to

Lindsay B. Carey

Lindsay.Carey@1atrobe.edu.au

Harold G. Koenig

Harold.Koenig@duke.edu

Jacinda R. Carey

Jacinda.Carey@latrobe.edu.au

1 Public Health Palliative Care Unit, La Trobe University, Melbourne, Australia

2 School of Medicine (Sydney), University of Notre Dame, Fremantle, Australia

3 St. Vincent's Private Hospital Sydney, Darlinghurst, NSW, Australia

4 Department of Psychiatry and Behavioral Sciences, Duke University Health Systems, Durham, $\mathrm{NC}$, USA

5 Department of Medicine, Duke University Health Systems, Durham, NC, USA

6 Department of Medicine, King Abdulaziz University, Jeddah, Saudi Arabia

7 Division of General Internal Medicine, Department of Medicine, Hospital Medicine Section, Weill Cornell Medicine, New York, NY, USA 
reach approximately 150 million by May 2021) and approximately 3 million people will have died. The top 20 nations with the highest number of cases and causalities are specified below (see Table 1). The US has the largest number of cases and deaths. Rather interestingly, China, from whence COVID-19 originated, is not among the leading nations (WHO, 2021). At the time of writing this editorial, China has reported only 102,867 cases and 4,851 deaths; however, this is far worse than some Pacific nations that have reported no cases and no deaths (e.g., Cook Islands, Tonga, Samoa) (WHO, 2021). Achieving population vaccination with any one of the COVID-19 vaccines is now a priority for all nations, if any semblance of normality is likely to return.

Within this current issue, a number of COVID-19 related topics are considered. The first article to commence this issue is (i) "valuing the spiritual," which highlights staff and patient costing benefits of spiritual care and chaplaincy, particularly relevant when one considers the effects of pandemics (e.g., SARS, Swine Flu, Avian Flu, and COVID-19). This commentary urges practical policy and research initiatives to maximize the impact of spiritual care for the benefit of patients, clinical staff, and health care organizations. Other COVID-19 articles in this issue note (ii) the collaboration of both public health officials and faith communities combating the COVID-19 contagion and resulting injustice among US citizens, (iii) psychological distress and religious coping experienced by Tunisians during COVID-19, (iv) a cross-sectional survey of Pakistani Muslims coping with health anxiety through religiosity during COVID-19, (v) anxiety reactions and coping modalities during COVID-19 based on a cross-sectional Israeli study comparing a population of religious patients with mental illness and their health caregivers, and (vi) a multivariate analysis examining factors predicting spiritual quality of life during COVID-19 among Canadian university employees and students. Two articles from the Philippines address the effects of COVID-19 upon their elderly residents: (vii) a pastoral reflection on suffering during the COVID-19 pandemic and (viii) a "song of hope" as a way of responding to the COVID-19 informational and psychospiritual needs of elderly residents. Finally (ix) there is an exploratory study which questions whether

Table 1 Nations with the highest COVID-19 cases and deaths (April, 2021). Source: WHO (2021). WHO-COVID-19 Statistics

\begin{tabular}{llllll}
\hline Country & Cases & Deaths & Country & Cases & Deaths \\
\hline USA & $30,304,462$ & 550,539 & Poland & $2,438,542$ & 54,941 \\
Brazil & $12,910,082$ & 328,206 & Colombia & $2,428,048$ & 63,777 \\
India & $12,485,509$ & 164,623 & Argentina & $2,373,153$ & 56,023 \\
France & $4,665,709$ & 95,875 & Mexico & $2,247,357$ & 203,854 \\
Russia & $4,580,894$ & 100,374 & Iran & $1,920,394$ & 62,999 \\
UK & $4,357,095$ & 126,826 & Ukraine & $1,745,709$ & 34,333 \\
Italy & $3,650,247$ & 110,704 & Peru & $1,568,345$ & 52,331 \\
Turkey & $3,445,052$ & 32,078 & Czechia & $1,551,896$ & 26,945 \\
Spain & $3,291,394$ & 75,541 & South Africa & $1,551,501$ & 52,954 \\
Germany & $2,885,386$ & 76,963 & Indonesia & $1,527,524$ & 41,242 \\
\hline
\end{tabular}


religion influences the motivations of Polish healthcare professionals to volunteer during a pandemic and (ix) a substantial study exploring affect balance and the psychological well-being of Church of England clergy and laity during the COVID-19 Pandemic.

\section{Sex}

Sex, and various issues related to sex, have always been a highly sensitive and often controversial topic. This issue examines a number of aspects of the discussion about sex: (i) the perspectives of religious families regarding boundaries and rules about sex, (ii) factors associated with support for adolescent access to contraception, (iii) religious adherence and the risks of sexually transmissible infections, (iv) the relationship between sexual compulsivity, emotional and spiritual distress of religious and non-religious internet pornography users, (v) the pornography debate and support for censorship, (vi) and a response that challenges the Islamic view concerning masturbation. Other issues relating to sex and gender include: (vii) whether physical alteration is a sufficient reason to prohibit ritual infant circumcision, (viii) whether invitro fertilization is a pastoral taboo, and (ix) the inclusion of elderly transgender and gender nonconforming people, their healthcare and theological ethics. While we make no value-based judgments on the findings or their interpretation, these articles do reflect the enormous breadth and complexity of the role of sex and sexuality in human life.

\section{Addictions}

A number of articles relating to substance use and addictions have been included: (i) smoking behaviors and viewpoints on smoking by theological students, (ii) a comparative examination of religion and health behaviors in relation to smoking among new US immigrants, (iii) the frequency of attendance at religious services and exposure to environmental tobacco smoke, (iv) the developmental trajectories of religious service attendance and predictors of nicotine dependence and alcohol dependence/abuse in early midlife, (v) the effect of spiritual coping, forgiveness, and gratitude following the completion of an alcohol addiction treatment program, (vi) predicting substance use based on religiosity/spirituality in individuals with cystic fibrosis, (vii) a study of a Christian 12-step program for smartphone-addicted adolescents, and lastly, (viii) an issue not always considered an addiction-gun violence - and the devasting aftermath of gun violence and faith-based responses.

\section{Women's Health}

As summarized by Goldin and Muggah (2020) in their international epidemiological collection Terra Incognita, "...gender inequalities and unequal power relations can stunt human development ... and countries will operate below their potential" 
(p. 191). To ensure gender equality, the optimal health of women is fundamental. JORH includes research regarding several ongoing issues that challenge women's gender rights, health issues, and the spiritual and/or religious care that is needed. One health concern for women in this issue relates to breast cancer, particularly: (i) women with newly diagnosed breast cancer, (ii) breast cancer and cervical cancer, (iii) religiosity level and patient mammography adherence, and (iv) spiritual wellbeing, depression and quality of life among breast cancer survivors. Two articles relate to maternity issues: (v) the mental health and quality of life of early pregnant women, and (vi) the important role of healthcare chaplains in perinatal post-mortem support. Finally, issues relating to women's religious beliefs, health, and life satisfaction are considered including (vii) the determination of dyadic adjustment, happiness, and related factors among married Turkish women living in Anatolia, (viii) the narratives of Shia Madurese displaced women in Indonesia regarding their religious identity and gender citizenship, (ix) opposition to the wearing of the Hijab, and lastly, (x) religious authority and vaccine hesitancy among ultra-orthodox Jewish mothers in Israel.

\section{Care of the Elderly}

There should be little surprise that care of the elderly is, and will become, increasingly important, simply because the "world's population is aging more rapidly than ever" (Goldin \& Muggah, 2020, p. 372). Articles within this issue consider the (i) characteristics of Danish centenarians' religious beliefs, (ii) determinants of selftranscendence and meaning in life among the elderly receiving institutional care, (iii) the effect of therapeutic touch on the comfort and anxiety of nursing home residents, (iv) mental disorders among older Islamic adults and caregiving practices, (v) the effect of religious therapy on the cognitive status of the elderly, and finally, (vi) the complex role and challenges inherent in the pastoral care of the elderly.

\section{Medical Education}

Lastly, in this issue, we also consider aspects relating to medical education, religion, and health: (i) medical residents and faculty coping with demanding issues through the use of religious, spiritual, and other personal strategies, (ii) the role of religion and physicians' outlook on death, dying, and end of life care, (iii) the perceived parameters of Christian pharmacy students' faith-sharing in clinical settings, (iv) the fundamental values of the Iranian-religious progress model of healthcare, (v) spirituality in clinical practice from the perspective of Brazilian medical students, and (vi) the "honey-making" of reflection that gives therapeutic power to the clinical encounter for both provider and patient. Finally, but certainly, by no means least, this section concludes with an important commentary 
on the need for the future training of academics and clinicians to conduct research in the associated areas of religion, spirituality, and health.

\section{Coming Issues}

Again, as noted in the previous editorial, the topic of moral injury (affecting military, civilian, and health care professionals) has been gaining increasing recognition particularly from a religious/spiritual perspective (Carey \& Hodgson, 2018). Further, this year marks two decades since that devastating event of September 11, 2001. Authors are encouraged to consider the topics of moral injury and/or September 11 for submissions through the Editorial Manager on the JORH web site: https:// www.springer.com/journal/10943/submission-guidelines.

\section{References}

Carey, L. B., Cohen, J., Koenig, H. G., \& Gabbay, E. (2021). COVID-19, Islam and Christianity. Journal of Religion and Health, 60(2), 621-624. https://doi.org/10.1007/s10943-021-01228-3

Carey, L. B., \& Hodgson, T. J. (2018). Chaplaincy, spiritual care and moral injury: Considerations regarding screening and treatment. Frontiers in Psychiatry, 9(619), 1-10. https://doi.org/10.3389/ fpsyt.2018.00619

Goldin, I., \& Muggah, R. (2020). Terra incognita: 100 maps to survive the next 100 years. London: Penguin.

JORH. (2021). Journal of Religion and Health, 60(3). New York: Springer Nature. https://link.springer. com/journal/10943/volumes-and-issues/60-3

WHO. (2021). WHO-COVID-19-Statistics. Geneva: World Health Organization.

Publisher's Note Springer Nature remains neutral with regard to jurisdictional claims in published maps and institutional affiliations. 